\title{
Motivating sustainable behavior: waste management and freshwater production on the Caribbean island of Saint Barthélemy
}

\author{
Lillian Howell \\ The University of the South, USA \\ howellr0@sewanee.edu \\ Russell Fielding \\ The University of the South, USA \\ russell.fielding@sewanee.edu
}

\begin{abstract}
Saint Barthélemy (St. Barth) is a Caribbean island located in the Leeward Islands of the Lesser Antilles. The island's small size, lack of natural resources, socioeconomic features, and geographic isolation make it an interesting case study for matters of sustainability, specifically freshwater production and waste management. Interviews were conducted with residents of the island to determine the factors that motivate or discourage sustainable behavior with regards to these environmental issues. A sense of civic duty, the simplicity of environmental regulations, rapid communication and implementation, socioeconomic stability and affluence, and economic incentives each served to promote environmental stewardship and sustainable decision-making, while government priorities and persistent habits tended to hinder such behavior. The results of this study could be applied to other island communities with similar characteristics to determine how we, as a global society, can move towards a more sustainable future.
\end{abstract}

Keywords: Caribbean, islands, Saint Barthélemy, sustainable behavior, waste management

https://doi.org/10.24043/isj.74

(C) 2019-Institute of Island Studies, University of Prince Edward Island, Canada.

\section{Introduction}

Saint Barthélemy, or St. Barth, is a small Caribbean island of about $23 \mathrm{~km}^{2}$ and approximately 9,500 permanent residents (Figure 1). Because of its size, isolation, and lack of natural resources, St. Barth has had to creatively address environmental issues such as freshwater production and waste management. For example, the mountainous terrain and lack of space make the prospect of future landfills difficult, and the absence of naturally occurring freshwater streams or reservoirs has created challenges for the island's growing population. In the past, waste was burned at the household level or dumped directly into the ocean, two methods of waste disposal which create obvious environmental impacts such as air and water pollution that could lead to public health and ecological issues. To obtain freshwater, cisterns were used for rainwater storage. Though these methods were adequate when the population was small, rapid rates of growth and modernization have since rendered such lifestyles impractical and insufficient. Since 2001, however, as a way to lessen the dependence upon fossil fuels for at least one energy-intensive activity, the island has relied on a waste-to-energy (WTE) facility where most waste is burned; thermal energy from the combustion process is then captured and sent to a desalination facility where seawater is converted to freshwater. The desalination plant is often a supplemental water resource for residents, who usually still utilize cisterns in their homes. 


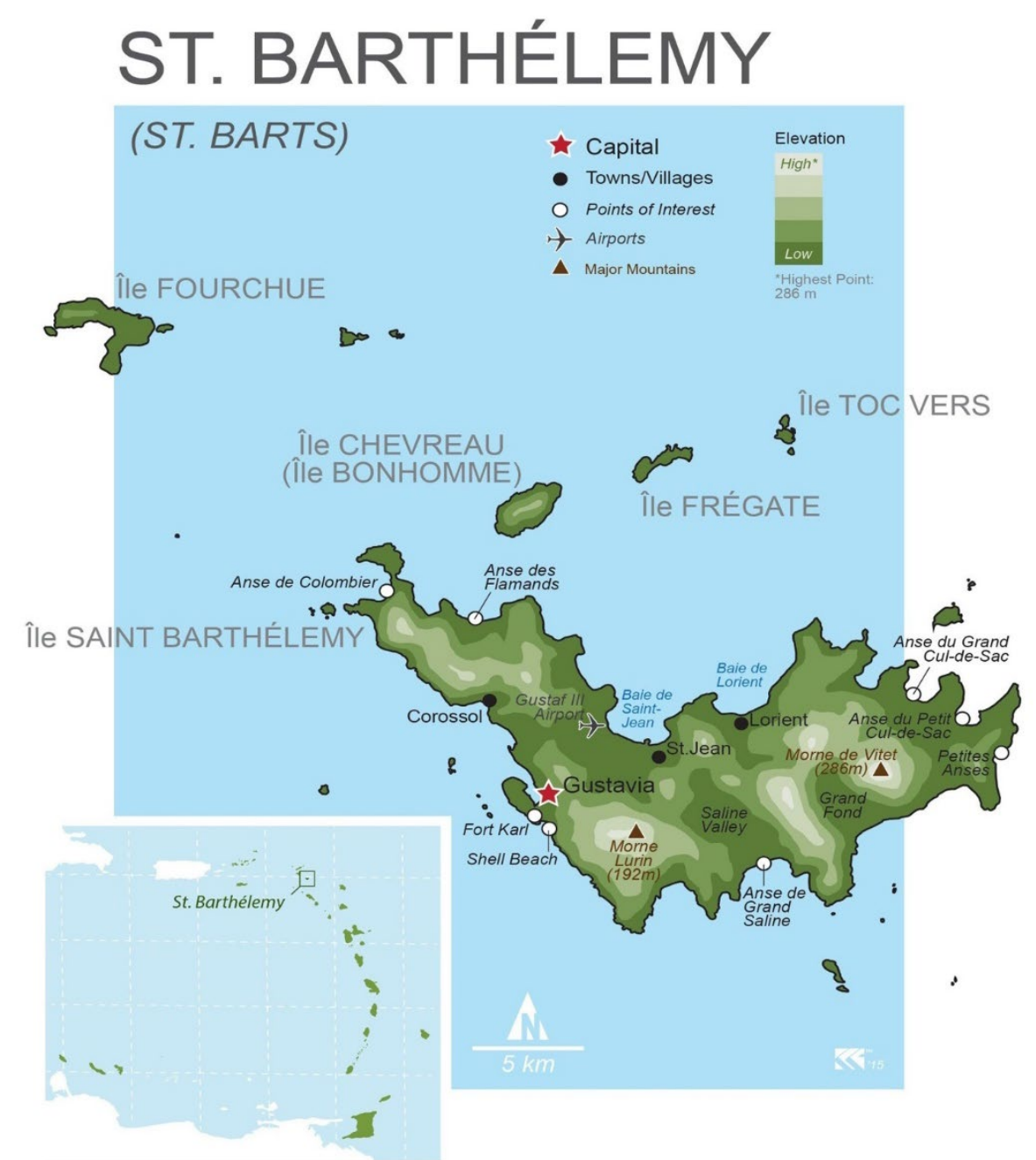

Figure 1: Map of Saint Barthélemy. Source: Cartography by K.M. Groom, Arizona State University, in Allen, 2017, p. 48.

This study sought to determine the factors which motivate or prevent sustainable behavior on St. Barth with regards to waste management, as well as freshwater production and consumption. In particular, we focus on the day-to-day behavior of individuals as contributions to the larger-scale, collective goals of creating and maintaining sustainable infrastructure systems on the island. The WTE-powered desalination plant allows St. Barth to moderate its reliance upon regional and global networks and to achieve, at least in the sectors of waste-management and freshwater provision, a modicum of self-sufficiency. In this way, the systems we discuss are part of St. Barth's efforts to be sustainable, not- to borrow a phrase from Karampela et al. (2017, p. 72) - "by isolating islands from the global socioeconomic system, but instead by incorporating them into the system on terms that are sensitive and sympathetic to their islandness and their local development." Specifically, the infrastructure developers on St. Barth have found a way to make use of the detritus from the island's globally sourced imports to lessen the island's reliance upon imported fuel and water. All that this novel, island-specific system requires is dependable buy-in from the island's residents.

\section{Background}

Sustainable island communities and decision-making

Research indicates that solving global environmental problems such as climate change begins with everyday decisions made at the household level (Barr, 2007; Gifford et al., 2011). In many 
cases, however, people will choose not to make a sustainable choice even when they are presented with two discernible options. According to Barr (2007), there are three overarching factors which prompt people to act environmentally or otherwise: environmental values, which include how one views herself in the context of the natural world; situational variables, such as age, political preference, and level of education; and psychological factors, such as the feeling that personal action will actually make a positive impact. Constructing social norms is also critical to influencing environmental decisions. If an individual believes that everyone around them is making a certain choice, they will be more likely to act. Much of it comes down to convenience and logistics, however. If an environmental practice is easy, cheap, and convenient, it is much more likely to be adopted by the members of a society.

An opposing view to Barr's can be found in that of environmental scientist Michael Maniates. He observes that small, individual decisions will not be able to create sustainable communities, especially when such decisions are driven by consumerism. In fact, by participating in so-called sustainable consumerism, one may only be perpetuating the very cycle that has reinforced environmental degradation for decades. Involvement in local government and community affairs, as well as positive changes toward sustainable decisionmaking at a higher level of government, will promote change at a greater scale (Maniates, 2001). Changing the mindset of a community, in some cases, may depend upon the decisionmaking of the governing body. Maniates argues that decisions made by a government may limit the choices available to consumers, thus constraining citizens to the options made available to them by local or even national policy-makers. For example, an individual may decide to take a bus to work each day rather than driving a personal vehicle, though they would really prefer to ride a bike. Because the government in this hypothetical situation does not provide bike lanes, the individual is confined to a limited set of choices. These two views, though in opposition, are key to understanding the situation in St. Barth. While the decisions of individuals can indeed have a notable impact on a small, well-connected island, this study determined that there were some environmental issues that could not be addressed without government action. Individual and government action are both key elements to creating a sustainable community in St. Barth, as they are mutually reinforcing drivers of change.

A study by Kinzig et al. (2014) argues that environmental behaviors can only be implemented if a society can change personal and social norms. In some cases, government policies are necessary to enacting this shift. Examples cited in the study include active norm management where the governing body attempts to influence norms through advertisements or campaigning. This particular policy instrument can be effective because it leads individuals to question their personal norms (Should I change my behavior to be a better member of society?) or their social norms (If most of my community cares about this issue, should I conform to be accepted?). The authors of the study also point out that if an individual feels that their action is causing harm to the community at large, they may feel more compelled to change their behavior (Kinzig et al., 2014). A second policy instrument that can be utilized by governing bodies involves what the authors call "changing the architecture influencing behaviors." By making a practice more convenient, people are more likely to comply. For example, recycling rates will increase if an individual does not have to sort their recyclables and if they have a curbside pickup service rather than a drop-off location (Kinzig et al., 2014).

A case study by Aitken et al. (2011) contends that two factors hinder climate change mitigation behavior in residents of New Zealand: powerlessness and the commons dilemma. If an individual did not feel like their action would make a notable impact, they would be less likely to change behavior or implement new habits. An individual may also be less likely to act if they feel that the rest of the community is not contributing (Aitken et al., 2011). Gifford et al. (2011) argues that environmental behavior is rooted in three key elements: personal norms, a belief that an environmental issue will jeopardize something that the individual values, and the belief that the individual's actions can mitigate the problem. Other 
factors such as economic barriers and availability of sustainable options may be at play (Gifford et al., 2011). Humans also have an intrinsic need to satisfy the immediate, short-term needs of oneself or one's group, sometimes at the expense of long-term, catastrophic challenges such as climate change (Vasseur \& Pickering, 2015).

The sum of the actions of individuals amounts to community-level impact. In the context of an island community with a small population, each member's contributions are proportionally more important in the determination of the community's overall sustainability. In order to create a community that is sustainable, defined by community planner Sharon Bailey (1990, p. iii) as "a community that is responsible, caring, empowered, healthy, and most importantly, in balance with nature," it is necessary to define the goals of the community as well as the values which should be upheld and practiced by its members. The values of individuals will only be changed when one is convinced that change is required, leading to a shift in lifestyle choices which reflect the values that are important to the community as a whole. Bailey (1990, pp. 39-40) states:

The building blocks of community are individuals. In order for a community to become sustainable in human and ecological terms, individuals must feel they are valued members of the community and in return they must act as responsible members of the community. A sustainable community requires that individuals cooperate for the greater good of the community, but it also recognizes that the individuals must be able to realize their full human potential.

If a person does not believe that their actions on a day-to-day basis will affect the overall well-being or outcome of the entire community, then their lifestyle and values will not change. Therefore, a sense of place or significance within society is critical to creating sustainable communities. Bailey contends that the creation of such communities occurs on three levels: physically, socially, and politically. In this way, the physical impact of a community on the environment can be minimized, the values of society can be established, and political influence can be strengthened to implement change into the community.

These behavioral trends can be more apparent in the context of island communities. Islands are geographically and culturally unique and must adapt to environmental issues differently than their continental counterparts. According to the geographer Stephen Royle (1989), at the 1985 United Nations Conference on Trade and Development, small size, isolation, transportation and communication difficulties, as well as limited internal economic opportunities were identified as challenges faced by developing islands in the Caribbean. Royle (1989, p. 111) also states that:

Smaller islands, whether nations or not, often face severe problems of how to provide their inhabitants with a living from an absolutely restricted resource base and/or find restrictions placed on their development because of the lack of, or shortage of, a necessary resource such as water.

Due in part to these challenges, sustainable resource management and the implementation of sound environmental policy is paramount. The rapid increase in both the permanent and seasonal populations of the island in recent years, due to an increase in tourism, places more strain on the environment and available resources. Similar to the subnational island jurisdictions surveyed by Gil and his contributors (2016, pp. 5-6), local authorities in St. Barth, with support of the public, seek to "balance ecological integrity with economic development and collective quality of life," through the development and maintenance of "a set of land use systems and social structures adapted to the particular natural constraints [i.e., aridity, insularity, smallness] and resources framed by available technologies." 


\section{Waste management}

As more people condense into a finite amount of space, the environment's capacity to handle waste reaches a limit. Collecting, treating, and disposing of trash has become a significant challenge for many island nations, therefore sound environmental policies for waste management must be enacted (Pariatamby et al., 2014). In many cases, islands simply do not possess enough space for a landfill (Rodríguez, 2011). In the past, it has been customary by many island societies to dump waste directly into the ocean. The negative environmental effects of this practice are obvious, though, fortunately, recent international agreements have succeeded significantly in lessening this method of waste disposal (Corti, 2013).

Waste-to-energy facilities (WTE) are becoming a common alternative for waste management. Based on a 2013 report, there are approximately 1,600 WTE facilities worldwide (Coenrady, 2013). The combustion process produces thermal energy, which can be used directly as heat or to create electricity. WTE is a concept that can help us to reframe how we view waste. Rather than seeing it as garbage that has lost all use or economic value, it can be used to create energy, reduce pollution, and save space from landfill conversion.

St. Barth built a WTE facility in 2001 to accommodate a growing amount of solid waste. Rather than generating electricity, however, the combustion of trash provides thermal energy to power the desalination plant, which accounts for about $40 \%$ of the island's demand in freshwater (Rodríguez, 2011). Rodríguez points out that the island itself, though small and primarily tourism-oriented, was able to have a WTE facility in place primarily because of its association with France (2011). St. Barth has been politically associated with France since 1659, except for an interlude of Swedish rule, lasting about a century, that ended in 1878 (Bourdin, 1978). Today, the island is an Overseas Collectivity of France (French: Collectivité d'Outre-Mer) and has a higher GDP per capita than nearly all other Caribbean islands. St. Barth is a wealthy territory of a highly developed nation which can provide knowledge and capital for a WTE facility to be successful. Hence, the WTE solution may not work for poorer islands where dumping is still customary and the tipping price of landfills is virtually nonexistent (Rodríguez, 2011). A campaign has been enacted to encourage residents to sort garbage at a household level. Categories of waste include paper, cardboard, organic waste, and plastic to be sent to the WTE facility, glass to be reused locally, metals to be exported and recycled, and batteries to be exported to Guadeloupe.

\section{Freshwater production}

Island nations face greater challenges regarding freshwater production because they often lack sufficient groundwater reserves or naturally occurring surface water. In the past, catchment of rainwater has been the primary source of water for people living on small, dry islands. However, as populations grow and climate change creates uncertainties, islands can quickly become vulnerable. Furthermore, the island's small size and isolation make it economically imprudent to rely uniquely on imported water. Desalination is often a viable solution to this issue (Fielding, 2014). The process of desalination, while it does reduce or remove the need to import water, is often heavily dependent upon fossil fuel combustion, as a recent case study of desalination in the Canary Islands makes clear (García-Rodríguez, et al., 2016). On St. Barth, the desalination plant meets about $40 \%$ of the island's demand for freshwater and its dependence upon fossil fuels is significantly decreased by the supply of energy from the WTE incinerator (Rodríguez, 2011). Only during periods of peak demand must the desalination plant supplement the energy obtained from the WTE with electricity created through fossil fuel combustion.

\section{Methods}

Twenty-two interviews were conducted with local inhabitants (64\% male, 36\% female; median age group 31-50 years), including four environmental activists, two government 
officials, one worker from the WTE facility, and one from the electricity facility. Other interviewees were employed in such sectors as the arts, journalism, and the service industry. The sample of participants is numerically small, as is the island's population. We do not claim to speak on behalf of all or even most residents of the island; rather, we intend to show trends among our sample of participants. All interviews were conducted in the participant's first language, which was most often French. Six participants were native to St. Barth, with the remaining participants originating in the United States, France, Belgium, and Guadeloupe. The median amount of time spent living on St. Barth was 16-20 years. The selection of participants occurred randomly as we met and interacted with residents and grew using the snowball method. Due to the small, well-connected nature of the island, it was not difficult to find more willing participants. To analyze the data, we coded responses into categories: opinions on waste management, water, government, tourism, and general attitudes toward the environment. We looked for trends and similarities of opinion that were then reviewed to draw conclusions. Though all interviews began with the same set of questions, these were often just a starting point that led to more in-depth discussion.

\section{Results}

Sustainable island communities and decision-making

All participants interviewed for this study contended that St. Barthélemy has undergone significant changes since they first moved to the island, or if they had lived on the island for a longer length of time, within the past 40 to 50 years. Respondents reported significant population growth and subsequently more construction, more cars, more noise, and in general a rapid modernization which has made the lifestyle of St. Barth more comfortable, allowing improved access to modern conveniences such as technology, imported foods, and other goods. Seventeen respondents associated these changes with various negative consequences, such as increased pollution and environmental degradation, as well as a general change in ambiance; the lifestyle is faster paced, infrastructure is more modern, and tourists now associate the island with luxury villas, restaurants, and yachts.

The economy of the island has also been transformed significantly. Respondents discussed the fact that prior to the 1960s, there were few economic opportunities available to residents apart from salt production, fishing, and shipping; however, this began to change when wealthy Americans such as David Rockefeller began to build vacation homes on St. Barth, opening the island as a new destination for high-end tourism.

According to an interview conducted with the island's president, the island is pursuing a "quality over quantity" approach, hoping to attract a smaller number of wealthy clients rather than accommodating more people in larger, cheaper resorts or hotels. A 2015 report by IEDOM claims that around $32.7 \%$ of private-sector jobs are in the restaurant and lodging sectors, which points to the importance of tourism for many residents' livelihoods (IEDOM, 2015). Eleven participants mentioned an ambivalent view of tourism in their interviews: they recognize that it is necessary to generate income and to improve the overall quality of life, though there is also a noticeable resentment of tourists and the impact they have had on their small community. Despite this resentment, the current economy is booming; according to an interview with the island's president, the government has no debt and the population has grown from 3,000 residents in 1980 to over 9,500 today.

\section{Waste management}

During interviews, it was recounted that as the island's economy and population continued to grow in tandem, it became necessary to address the issue of waste management, for more people and more economic activity inevitably generate more waste. A common local perception is that the island's small size, mountainous terrain, and high economic value of the 
land preclude the possibility of a landfill. From the waste management employees we learned that, in 2002, there were 6,000 tons of trash produced; in 2015 there were 11,000. Before the island's "transformation" (i.e., its shift toward high-end tourism and sustainable waste management), residents report that it was customary to either dump waste directly into the ocean or to burn it at home. One respondent remembers that, as a child, he was on a boat near the island and saw an old refrigerator floating in the water. This anecdote illustrates the obvious environmental impacts of this method of waste disposal. In order to accommodate the growing amount of trash, an incinerator was built in 2001 which accommodates all waste apart from glass, metal, and other used objects such as dishwashers or cars that cannot be burned. Residents have been asked to sort their trash at home to make this process more efficient. One bin is designated for combustible waste, while another is specifically used for glass and metal and requires a clear trash bag. During a tour of the facility, we were shown that glass is ground up into a sand-like substance to be repurposed, metal must be exported for later recycling, and all other waste is burned. The ashes are then packed and exported to Europe.

When questioned about the waste-sorting regulation, all 22 respondents reported that they participate. Fifteen find the system easy and convenient, while the remaining participants did not state their opinion. Because there are only two bins (as opposed to four or more as in other countries), and because many residents are served by a truck that picks up garbage directly from their home, it is easy to participate. Combustible waste is picked up every day except Sundays and holidays, while glass and metal are picked up once per week. Two bins are usually available in public places such as community spaces, beaches, and restaurants. Participants also report being well-educated about the regulation. Ads have appeared in newspapers and on the radio, which explain how to sort and why sorting is necessary. These campaigns were reported by 2 participants to have improved the success of the regulation significantly, and because of the island's small size, it was easy to spread information and to implement the regulation effectively. Negative reinforcement has also played a role in its successful implementation. If a truck comes to remove garbage and sees that a bag is not properly sorted, the garbage collector will place a sticker that reads "pas conforme" or "not conforming" on the bag and will not take the bag to the incinerator.

Despite the overall success of this regulation, the waste-sorting system is not perfect, and this was evident during interviews. Eight participants reported knowing others who simply choose not to participate because they do not care, they do not want to change their habits, or they are not well-educated on the proper behavior. For example, some people still burn their trash at the residential level, not because it is more convenient, but because that has been a part of their lifestyle and they do not want to change their habits. Others may not want to pay for the trash pick-up service which costs 110 Euros (US\$120) per year for households and up to 1,000 Euros (US\$1093) per year for businesses. Twelve participants made a point of saying that that this mindset was the minority, however. According to an incinerator employee, sorting has improved dramatically in recent years due to increased communication and education, though they do still employ someone to do an additional round of sorting once waste reaches the incinerator.

Two respondents reported that the waste management system is not always convenient for them. Due to the steep terrain of St. Barth, there are certain private roads which are not accessible to garbage trucks. Therefore, some people must bring their trash to the incinerator directly. Traffic can also be heavy at the incinerator in the morning and going out of one's way to dispose of their trash can be somewhat burdensome. Furthermore, three interviewees said they believed there were not adequate trash bins in public spaces.

Issues related to the potential for composting at a municipal scale was also a frequent topic in our conversations. St. Barth produces large amounts of plant waste, food waste, tree trimmings, and other forms of organic waste. Some respondents considered the possibility that composting would not only divert waste from the incinerator, but it would also make use of 
available nutrients to create a usable product. The island's president claimed during his interview that land has already been purchased for a composting facility, though construction has yet to begin. Two participants report that the construction of the facility has been delayed multiple times, though the reason for the delay was not clear. The president also reported that the facility is a 16 million Euro investment (US $\$ 16,968,800)$. The compost produced by the facility will be used locally to maintain landscaping and gardens and would reinforce the island's vegetation in the event of a hurricane, such as Hurricane Irma which hit the island in 2017. It may also deter people from burning organic waste at home. One participant was hesitant to compost if it required an additional bin for sorting, while another had concerns about the facility being placed near their home. Eight residents expressed support for composting and believed it would be beneficial to St. Barth, while the remaining participants expressed no opinion.

\section{Freshwater production}

Nine residents interviewed reported that a cistern is their primary source of freshwater. St. Barth currently receives regular yet meager rainfall that is captured and stored under homes. In fact, many of the roofs in St. Barth have been constructed specifically to catch and drain water into a cistern. For many people, cisterns meet all of their household water needs, excluding drinking water. In the past, there were reported health problems that arose from drinking water from cisterns without a filter, but today the majority of residents do not directly drink water from cisterns, and they also have filters in place to clean the water before use for other household needs as an extra precaution.

There were varied results from participants regarding opinions on future freshwater security. Five participants believed that as long as there is rainfall and money to operate the desalination plant, freshwater will always be available; they were generally not concerned with future water security. In five different cases, interviewees expressed concern that water scarcity could become a problem if rainfall patterns decrease in the future or, if patterns of growth and development were to continue unabated, the island would not be able to meet the demands of large hotels, swimming pools, thirsty landscaping, and an increasing number of large homes and villas. It was reported in one interview that the current water infrastructure is at its limit during peak tourism times which may suggest that in the future the current freshwater production infrastructure will become insufficient.

One major component of the freshwater system in St. Barth is a reliance on bottled water for drinking water. The consumption of bottled water is imbued in the culture. When questioned about bottled water, it seemed for most people to be a question of preference; people prefer bottled water because it is cold, has a better taste, and contains minerals. There did not seem to be any real health concern about drinking the water from the desalination plant, although no research has been done regarding the quality of this water. While 11 participants reported that they only drink bottled water and do not see any problem with it, there were two participants who expressed concern that it creates social and environmental issues. For example, if a shipment of bottled water failed to reach St. Barth, the island would be left vulnerable and without a local drinking water resource. The price of bottled water will also continue to rise, which could in the future put financial strain on families. Environmental issues brought up by these two residents include the carbon footprint of importing water from France, Fiji, or other distant places. In addition, the used bottles create large quantities of plastic waste which are incinerated. Not only is this more expensive but the burning of plastic can release harmfuloften carcinogenic - pollutants such as dioxins. Plastic waste also often finds itself in the ocean which is extremely harmful to marine biodiversity and ecosystems (Derraik, 2002).

\section{Government}

There was some degree of variation among surveyed residents regarding their opinion of the government and its attitude towards sustainability. Six participants expressed confidence that 
the government wants to protect the environment, as evidenced by government-run environmental agencies, as well as their desire to maintain the "pristine" image of the island. According to some, it is difficult to obtain building permits and the presence of "green zones" prevents excessive development.

The more overwhelming opinion from 13 residents contended that the government does not care about the environment or does not do enough to protect it, either because they are allowing too many construction permits that create pollution and attract more tourists, or they believe that the rules for building permits are vague and easy to get around. It was noted in one interview that "under the table" deals have been made to allow for building in green zones. According to one resident who is involved in environmental activism, she will get calls about construction happening in green zones, though when she reports this activity to the government they fail to act or enforce the zoning regulation. The government also boasts that $75 \%$ of the island is considered a green zone, though much of those areas exist in steep places where construction would not be possible in the first place. Therefore, it has been in the hands of the public to attempt to prevent excessive development. For example, there were plans to build a hotel on Saline Beach, one of the island's more pristine areas, but plans were halted due to an overwhelming public outcry. Frustration was a common theme throughout the interviews, as three participants pointed out that the government has the financial means to promote environmental stewardship, but they often choose not to act because their priorities lie in economic development. A participant also acknowledged that the government lacks long-term vision for the development of the island.

The president's opinion, as seen in his interview, is that, because St. Barth is a democracy, the government cannot deny people the right to live there or to build on their property. He also contends that the government's goal is merely to improve what already exists, rather than to build new infrastructure, despite the observed increase in new construction occurring since Magras took office in 2007. In his opinion, the success of the island can be observed in its economic success and its social stability, and in his words, "pour l'instant, tout se passe bien," or "for now, everything is going well."

\section{Discussion}

\section{Interpretations}

This case study of Saint Barthélemy indicates that there are multiple factors which either motivate or discourage sustainable behavior. Based on testimonies from those interviewed, civic duty is a strong motivator of sustainable behavior. Because of the island's small size and isolation, residents feel a sense of connection towards other members of the community and to the island itself. Due to this connectivity, residents feel as though the decisions they make from day to day will actually have an effect on the well-being of the entire community. The community itself is not composed of nameless, faceless "others," but rather they are friends, family, colleagues, neighbors. In order to participate positively in the community and to feel like as though they are accepted by the community, residents are led to make sustainable decisions, one example being compliance with the waste-sorting regulation.

Simplicity is also a key factor to sustainable behavior in St. Barth. The process of wastesorting is, for the most part, convenient and easy to comply with. Most individuals do not want to spend a large part of their day dealing with their own waste; they prefer for it to disappear as quickly and quietly as possible. Because there are only two bins in which to sort, because the process of having waste taken to the incinerator is not entirely cumbersome, and because bins have been placed relatively consistently throughout the island, it is not difficult to do the right thing.

In addition, the size of the island also facilitates rapid communication and implementation. For example, when the waste-sorting regulation was first instated, it was not as widely successful as it is today (Fielding, 2014). As a result, ads were run in newspapers and 
on the radio to educate inhabitants about the importance of compliance. This strategy proved very effective; the small, community-focused nature of the island was important to its integration into society. News and information can travel quickly, and because people are so connected to one another, it is easier for norms to take hold in their community.

Furthermore, St. Barth can be considered a very socioeconomically stable island. The island has no debt, there are no impoverished areas, and the majority of the population is well-educated. For this reason, residents can afford to think beyond short-term needs. Food, water, and access to education and employment are not the primary concerns of most inhabitants; therefore they have the time and resources to think about long-term issues such as sustainability and the environment. The government of St. Barth can also afford to invest in sustainable infrastructure such as a desalination plant, and (potentially in the future) solar panels and a composting facility.

Finally, the island has an economic incentive to consider the environment. When tourists vacation in St. Barth, they expect a certain level of environmental quality; that is to say they expect clean beaches, clean water, clean air, and the appearance of an untouched, serene paradise. Therefore, due to the economy's reliance on tourism, there are incentives to maintain the environment to meet the demands of tourists.

On the other hand, there are several factors that discourage sustainability in St. Barth. At present, the most powerful source of prevention is the government. Based on the perspectives of interviewees and from speaking directly with members of the government, it is clear that they are running the island like a business, or, in other words, economic progress is at the forefront of their priorities. It seems as though the government is only focused on protecting the environment as it pertains to the economy, and therefore they often overlook long-term needs in favor of short-term benefits. For example, development is often prioritized over conservation, as evidenced by their failure to comply with zoning regulations. This allows for short-term gains, but eventually excessive development will degrade the environmental quality of the island and create long-term issues such as biodiversity loss, pollution, and inability to provide resources.

Due to the rapid transformation of St. Barth, both culturally and economically, it has been challenging for some residents to keep up with the pace of change that has been occurring since the 1960s and 70s. Urbanization, modernization, and population growth have created new environmental issues that, before the "transformation," residents of St. Barth did not have to face. Today, these changes put pressure on the environment, creating a necessity to comply with new regulations and to make general lifestyle changes. Often it is difficult for people to simply change their habits, especially if they have grown up practicing a certain way of life. Some people still burn their trash at home, simply out of habit. Other people do not see an issue with throwing an empty bottle directly into the ocean. It is reported that certain businesses will dump their liquid waste directly into the environment, rather than disposing of it safely and in a way that is not environmentally detrimental. All of these examples reflect an attitude that should reside in the past. The sharp growth in population requires that each citizen of St. Barth think for the greater good of the community, for if even one person acts otherwise it could reverberate throughout the entire island.

\section{Significance}

Any community could be analyzed to determine the factors that either motivate or discourage sustainable behavior; the results of this study can be transferred to apply to other locations based on similar characteristics. Saint Barthélemy is a small, isolated, affluent Caribbean island. When considering sustainability in St. Barth, one must also consider these characteristics which inevitably influence how residents think about the environment and choose to behave on a day-to-day basis. Other small communities, whether an island or not, could consider how the connection to place and to other community members could influence sustainable 
decision-making. Furthermore, it may suggest that environmental regulations are better implemented at a local level rather than at a national scale. It is also worth considering the socioeconomic situation in St. Barth. Perhaps these findings are best applicable to more affluent communities where people are more likely to be able to think beyond their own basic needs. The isolated nature of the island also makes St. Barth more vulnerable to environmental hazards, and environmental issues are more likely to take hold more quickly and on a greater scale. As a result, it is even more important for issues to be addressed proactively, rather than reactively, a concept that could be applied to other isolated or island communities.

Island communities, with their limited resources and increased vulnerability to environmental change, can be viewed as microcosms of environmental awareness. One island scholar noted the sadly ironic nature of islands, focusing specifically upon St. Barth along with France's other overseas territories, characterized by "low greenhouse gas emissions [and] high vulnerabilities" to the effects of climate change (Ferdinand, 2018, p. 122). In this and other ways, the challenges faced by island communities like St. Barth may predict the future of all communities. Limited space, finite water resources, waste accumulation, air pollution, overpopulation, and lack of energy autonomy are all issues that are exacerbated by the small, isolated nature of islands (e.g., Dodds, 2007; Banos-González, et al., 2016; Tiago, et al., 2016). But as the population continues to grow across the globe, these environmental issues will worsen everywhere.

At the same time, we can also look to how islands like Saint Barthélemy overcome environmental challenges. They build and mobilize community, they innovate, and they recognize that even contributions as simple as an individual's daily waste-sorting can make an impact. In this way, the narrative of waste management in St. Barth offers a case of 'counternarrative' to the common discourse of unmitigated small island vulnerability as discussed by Kelman (2018, p. 149). Empirical evidence indeed supports the notion of specific vulnerabilities found in high concentrations on small islands. Research by Kelman and others (e.g., Briguglio \& Kisanga, 2004) also provides examples of 'island resilience' (Kelman, 2018, p. 149), a broad category of processes by which island communities identify, plan for, and mitigate against economic and environmental issues such as tourism management, waste management, freshwater provision, and even broader, more complex issues such as climate change.

\section{Acknowledgements}

The authors would like to thank the Biehl International Research Fellowship program at the University of the South for its funding of this project. We would also like to thank the citizens of St. Barth who participated in this study and helped along the way, especially Ellen LampertGréaux and Rosemond Gréaux who welcomed us with open arms. The manuscript was improved by the thoughtful comments of the Island Studies Journal editor and anonymous reviewers. This research was conducted under IRB approval through the University of the South, Sewanee, Tennessee. Document number: 16S-24.

\section{References}

Aitken, C., Chapman, R., \& McClure, J. (2011). Climate change, powerlessness and the commons dilemma: assessing New Zealanders' preparedness to act. Global Environmental Change, 21, 752-760. https://doi.org/10.1016/j.gloenvcha.2011.01.002

Allen, C.D. (Ed.). (2017). Landscapes and landforms of the Lesser Antilles. New York: Springer.

Bailey, S. (1990). Creating sustainable communities (Unpublished master's thesis). University of British Columbia, Vancouver, BC.

Banos-González, I., Martínez-Fernández, J., \& Esteve, M.Á. (2016). Tools for sustainability assessment in island socio-ecological systems: an application to the Canary Islands. Island Studies Journal, 11(1), 9-34. 
Barr, S. (2007). Factors influencing environmental attitudes and behaviors. Environment and Behavior, 39(4), 435-473. https://doi.org/10.1177/0013916505283421

Bourdin, G. (1978). Histoire de St. Barthélemy. New York: Porter Henry.

Briguglio, L., \& Kisanga, E.J. (Eds.) (2004). Economic vulnerability and resilience of small states. Msida: Islands and Small States Institute.

Coenrady, C. (2013). 1600 Waste to energy-facilities in the World. www.seas.columbia.edu/earth/wtert/sofos/WTE Plants.xlsx.

Corti, A. (2013). Differentiating the methods of waste treatment in the wider Caribbean region (Unpublished master's thesis). Uppsala University, Uppsala, Sweden.

Derraik, J. (2002). The pollution of the marine environment by plastic debris: a review. Marine Pollution Bulletin, 44(9), 842-852. https://doi.org/10.1016/S0025-326X(02)00220-5

Dodds, R. (2007). Malta's tourism policy: standing still or advancing toward sustainability? Island Studies Journal, 2(1), 47-66.

Ferdinand, M. (2018). Subnational climate justice for the French Outre-mer: postcolonial politics and geography of an epistemic shift. Island Studies Journal, 13(1), 119-134. https://doi.org/10.24043/isj.49

Fielding, R. (2014). "The good garbage": waste to water in the small island environment of St. Barthélemy. Focus on Geography, 57(1), 1-13. https://doi.org/10.1111/foge.12024

García-Rodríguez, J-L., García-Rodríguez, F.J., \& Castilla-Gutiérrez, C. (2016). Human heritage and sustainable development on arid islands: The case of the Eastern Canary Islands. Island Studies Journal, 11(1), 113-130.

Gifford, R., Kormos, C., \& McIntyre, A. (2011). Behavioral dimensions of climate change: drivers, responses, barriers, and interventions. WIREs Climate Change. https://doi.org/10.1002/wcc. 143

Gil, A. (2016). Sustainable development and environmental conservation in the Outermost European Regions. Island Studies Journal, 11(1), 5-8.

IEDOM (2015). Saint Barthélemy, Rapport annuel 2015. https://www.iedom.fr/IMG/pdf/ra2015 saint-barthe lemy.pdf

Karampela, S., Papazoglou, C., Kizos, T., \& Spilanis, I. (2017). Sustainable local development on Aegean Islands: a meta-analysis of the literature. Island Studies Journal, 12(1), 71-94. https://doi.org/10.24043/isj.6

Kelman, I. (2018). Islandness within climate change narratives of small island developing states (SIDS). Island Studies Journal, 13(1), 149-166. https://doi.org/10.24043/isj.52

Kinzig, A.P., Ehrlich, P.R., Alston, L.J., Arrow, K., Barrett, S., Buchman, T.G., Daily, G.C., Levin, B., Levin, S., Oppenheimer, M., Ostrom, E., \& Saari, D. (2013). Social norms and global environmental challenges: the complex interaction of behaviors, values, and policy. Bioscience, 63(3), 164-175. https://doi.org/10.1525/bio.2013.63.3.5

Maniates, M. (2001). Individualization: plant a tree, buy a bike, save the world? Global Environmental Politics, 1(3), 31-52. https://doi.org/10.1162/152638001316881395

Pariatamby, A., \& Periaiah, N. (2014). Waste management challenges in sustainable development of islands. http://repository.um.edu.my/86091/1/ISWA Full Paper, Final.pdf.

Rodríguez, M. (2011). Cost-benefit analysis of a waste-to-energy plant for Montevideo and waste-toenergy in small islands (Unpublished master's thesis). Columbia University, New York.

Royle, S.A. (1989). A human geography of islands. Geography, 74(2), 106-116.

Tiago, T., Dias-Faria, S., Cogumbreiro, J.L., Couto, J.P., \& Tiago, F. (2016). Different shades of green on small islands. Island Studies Journal, 11(2), 601-618.

Vasseur, L., \& Pickering, G. (2015). Feeding the social animal: how to engage Canadians in climate change mitigation. In C. Potvin, S. Aitken, F. Berkes, L. Margolis, \& M. Stoddart (Eds.) Acting on climate change: extending the dialogue among Canadians (pp. 166171). Montreal: Sustainable Canada Dialogues. 